\title{
High seroprevalence of SARS_COV-2 in Bergamo: evidence for herd immunity or reason to be cautious?
}

\author{
Carlo Signorelli ${ }^{1}$ - Alberto Zucchi ${ }^{2} \cdot$ Carlo Alberto Tersalvi $^{2} \cdot$ Roberta Ciampichini $^{1} \cdot$ Elvira Beato $^{2}$. \\ Federica Balzarini ${ }^{2} \cdot$ Anna Odone $^{3} \cdot$ John Middleton ${ }^{4}$
}

Received: 13 November 2020 / Accepted: 16 November 2020 / Published online: 20 November 2020

(C) Swiss School of Public Health (SSPH+) 2020

We report $42 \%$ Severe Acute Respiratory Syndrome Coronavirus 2 (SARS-CoV-2) antibodies' seroprevalence in one province of Northern Italy and its effect on the second wave. This is one the highest level recorded so far in European seroprevalence studies. We believe this needs to be carefully considered in the context of the current scientific debate about the herd immunity approach to control the COVID-19 outbreak (Aschwanden 2020; Doshi 2020; Omer et al. 2020). Italian public health and political authorities have never considered herd immunity to be the solution to counteract the COVID-19 epidemic (Aschwanden 2020); however, some recent epidemiological data show how this indirect form of protection might begin to have some relevant effects on the progress of the pandemic in Northern Italian Regions.

The second wave of the COVID-19 epidemic in Italy occurred about two weeks later than in other large European countries, but just as heavy (Odone et al. 2020; Signorelli et al. 2020c). In October 364,569 new cases were reported and 2724 deaths with 4,450,539 tests performed (7417/100 000 population). The COVID-19 burden and infection spread mainly in northern-central metropolitan areas (Milan, Genoa, Turin) and the largest towns in

This project has received funding from the European Union's Horizon 2020 research and innovation programme under grant agreement No 101003562 .

Carlo Signorelli

signorelli.carlo@hsr.it

1 School of Medicine, University Vita-Salute San Raffaele, Via Olgettina, 58, 20132 Milan, Italy

2 Local Health Authority (ATS) of Bergamo, Bergamo, Italy

3 Department of Public Health, Experimental and Forensic Medicine, University of Pavia, Pavia, Italy

4 The Association of Schools of Public Health in the European Region (ASPHER), Brussels, Belgium
Lombardy, the region where the first European autochthonous cause of COVID-19 was identified on February 20th (Signorelli et al. 2020a, b, c). As the second wave came, the response of the Italian government authorities was not as rapid as in the first phase, when the national lockdown was imposed on March 8th (Signorelli et al. 2020c). Such delay was also determined by fear of the social and economic consequences of the restrictions. This resulted in moderate and less effective mitigation measures, including: coffee shops, and restaurants closing early in the afternoon, curfew, distance learning, smart working and closed gyms and swimming pools. In the last two weeks of October, the impact of the pandemic was particularly violent, although, fortunately, case-fatality dropped considerably (Signorelli and Odone 2020), from 12.6\% in the two months of February 20-20 April to $0.5 \%$ in the period August 20-October 20 (Table 1). However, indepth analysis of Lombardy data offers some further points of interests. The province of Bergamo (1.116 million inhabitants) was the most heavily hit by COVID-19 in the first phase of the epidemic, with 18,545 cases (1661/ 100,000) and 7740 deaths $(693 / 100,000)$. This was the largest burden in Italy and one of the largest in Europe. In order to assess the real impact of the epidemic, a series of serological surveys were conducted in Bergamo in June and July 2020 (data not published, collected by the authors, officers of the Local Health Authority). The seroprevalence studies involved 115,000 subjects (adults, mainly workers coming back from lockdown or quarantine periods) with a reported seroprevalence ranging from $42 \%$ in the east district to $22 \%$ in the west district. The incidence data of the second wave in the province of Bergamo, compared with the neighboring metropolitan provinces of Milan and Monza (much less affected in the first phase) are reported in Table 2 and Fig. 1. Even within the same local health authority of Bergamo (ATS), differences in the incidence of COVID-19 during the second wave between the West 
Table 1 COVID-19 agespecific Case Fatality Rates (CFRs) in Italy
Table 2 October, 2020: COVID-19 incident cases and incidence rates (per 100,000 pop) in selected Italian northern provinces

\begin{tabular}{|c|c|c|c|c|c|c|}
\hline \multirow[t]{2}{*}{ Age group } & \multicolumn{3}{|c|}{ February 20-April 16} & \multicolumn{3}{|c|}{ August 18-October 20} \\
\hline & Deaths (n) & CFR $(\%)$ & Cases (n) & Deaths (n) & CFR $(\%)$ & Cases (n) \\
\hline 0-19 & 1 & 0.0 & 2927 & - & 0.0 & 28,601 \\
\hline $20-29$ & 7 & 0.1 & 7737 & 1 & 0.0 & 28,722 \\
\hline 30-39 & 40 & 0.3 & 11,686 & 4 & 0.0 & 23,842 \\
\hline $40-49$ & 178 & 0.9 & 20,519 & 8 & 0.0 & 24,949 \\
\hline $50-59$ & 756 & 2.5 & 29,858 & 47 & 0.2 & 26,241 \\
\hline $60-69$ & 2284 & 9.5 & 24,040 & 79 & 0.5 & 15,059 \\
\hline 70-79 & 6203 & 24.1 & 25,717 & 197 & 2.1 & 9310 \\
\hline$\geq 80$ & 10,525 & 28.8 & 36,519 & 463 & 5.3 & 8749 \\
\hline Total* & 19,996 & 12.6 & 159,107 & 798 & 0.5 & 165,473 \\
\hline
\end{tabular}

*Unknown cases are counted but not shown in the table

\begin{tabular}{lcll}
\hline Province & No. cases in October & Population (millions) & Monthly Incidence rate \\
\hline BERGAMO & 2875 & 1.116 & $257.6 / 100,000$ \\
MILANO & 40,431 & 3.196 & $1264.7 / 100,000$ \\
MONZA e BRIANZA & 11,203 & 0.878 & $1275.5 / 100,000$ \\
\hline
\end{tabular}

-Bergamo - Milan

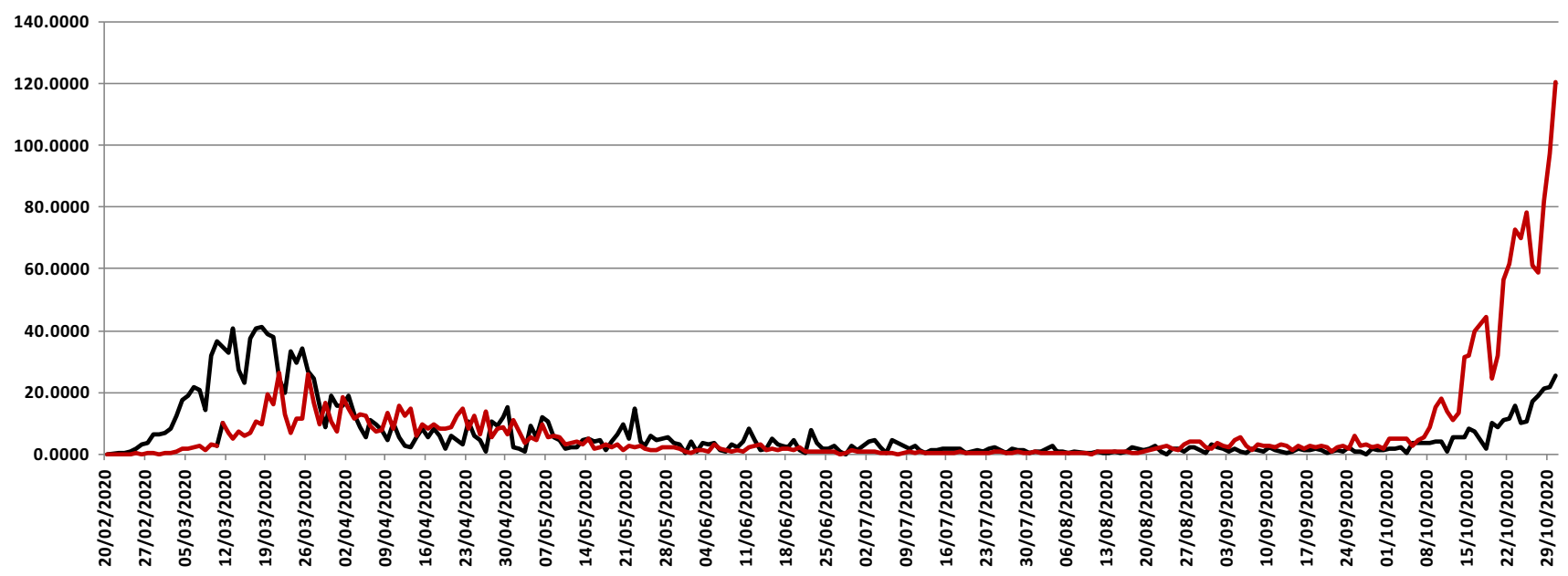

Fig. 1 COVID-19 burden over time in Bergamo and Milan (Italy). Daily incidence rates comparison

Table 3 Wave $1 *$ versus Wave $2 * *$ : COVID-19 incident cases and incidence rate (per 100,000 pop) in Bergamo and its districts (Italy)

\begin{tabular}{|c|c|c|c|c|c|}
\hline DISTRICT & Population & $\begin{array}{l}\text { No. cases wave } \\
1\end{array}$ & $\begin{array}{l}\text { No. cases wave } \\
2\end{array}$ & $\begin{array}{l}\text { Wave1 Incidence rates (per } \\
100,000 \text { ) }\end{array}$ & $\begin{array}{l}\text { Wave2 Incidence rates (per } \\
100,000 \text { ) }\end{array}$ \\
\hline $\begin{array}{r}\text { BERGAMO } \\
\text { CENTRAL }\end{array}$ & 251,865 & 3660 & 535 & 1453.2 & 212.4 \\
\hline BERGAMO EAST & 383,957 & 5841 & 697 & 1521.3 & 181.5 \\
\hline BERGAMO WEST & 480,104 & 5373 & 1643 & 1119.1 & 342.2 \\
\hline Total & $1,115,951$ & 14,874 & 2875 & 1332.9 & 257.6 \\
\hline
\end{tabular}

*Wave 1: 20-Feb to 30-Jul, 2020

**Wave 2: 01-Aug to 31-Oct, 2020 
district and the East district were detected (Table 3). These data might help to understand and project the evolution of the epidemiological picture if the availability of an effective vaccine were to be delayed and the containment and mitigation measures were not able to control the epidemic (Middleton et al. 2020). It is not possible to exclude that in the most affected areas in the first phase there were less risky behaviors later on. However, it is possible that seroprevalence levels above $40 \%$ might reduce the circulation of the virus due to the higher proportion of non-susceptible individuals; and prevent $\mathrm{R}(\mathrm{t})$ from rising above 1 . This might therefore reduce further epidemic waves with consequent impacts on the national health system and on the hospital emergency units of the Region.

It is too early to conclude that there is evidence of herd immunity emerging in Bergamo. Early hopes of herd immunity at the much higher level of sero-prevalence observed (66\%) after the 1st wave of COVID-19 in Manaus in the Brazilian Amazon region (Buss 2020) are now giving way to disappointment as the area experiences a resurgence of the virus (Financial Times 2020). We wish to see rising levels of seropositivity reflecting previous exposure to the virus to give us hope that the pandemic can get past its peak. However unless we are able to find a reasonably effective vaccine, we must remain vigilant and continue to apply our containment and mitigation 'lockdown' measures. It is necessary for public health authorities to continue to monitor seroprevalence in population unbiased studies to understand how the pandemic is evolving, and how population immunity is developing. It is however, too early to say categorically that there is, or will be herd immunity at a certain level of seroprevalence, estimated to be $60 \%$ in a recent contribution (Omer et al. 2020). It is therefore dangerous, and unfounded in the science, to advocate use of herd immunity as a means to pandemic control at this time.

\section{References}

Aschwanden C (2020) The false promise of herd immunity for COVID-19. Nature 587:26-28. https://doi.org/10.1038/d41586020-02948-4

Buss L (2020) COVID-19 herd immunity in the Brazilian Amazon Lewis FB COVID-19 herd immunity in the Brazilian Amazon. medRxiv 2020.09.16.20194787; https://doi.org/10.1101/2020. 09.16.20194787

Doshi P (2020) Covid-19: Do many people have pre-existing immunity? BMJ (Clinical research ed) 370:m3563. https://doi. org/10.1136/bmj.m3563

Financial Times (2020); Hotspots of resurgent Covid erode faith in herd immunity. https://www.ft.com/content/5b96ee2d-9ced46ae-868f-43c9d8df1ecb. Accessed 11 Nov 2020

Middleton J, Lopes H, Michelson K, Reid J (2020) Planning for a second wave pandemic of COVID-19 and planning for winter: a statement from the Association of Schools of Public Health in the European Region. Int J Public Health. https://doi.org/10. 1007/s00038-020-01455-7

Odone A, Delmonte D, Scognamiglio T, Signorelli C (2020) COVID19 deaths in Lombardy, Italy: data in context. The Lancet Public Health 5:310. https://doi.org/10.1016/s2468-2667(20)30099-2

Omer SB, Yildirim I, Forman HP (2020) Herd Immunity and Implications for SARS-CoV-2 Control. Jama 5:2. https://doi.org/ 10.1001/jama.2020.20892

Signorelli C, Odone A (2020) Age-specific COVID-19 case-fatality rate: no evidence of changes over time. Int $\mathrm{J}$ Public Health 65:1435-1436. https://doi.org/10.1007/s00038-020-01486-0

Signorelli C et al (2020a) COVID-19 mortality rate in nine highincome metropolitan regions. Acta Bio-Medica Atenei Parmensis 91:7-18. https://doi.org/10.23750/abm.v91i9-s.10134

Signorelli C et al (2020b) The spread of COVID-19 in six western metropolitan regions: a false myth on the excess of mortality in Lombardy and the defense of the city of Milan. Acta Bio-Medica Atenei Parmensis 91:23-30. https://doi.org/10.23750/abm.v91i2. 9600

Signorelli C, Scognamiglio T, Odone A (2020c) COVID-19 in Italy: impact of containment measures and prevalence estimates of infection in the general population. Acta Bio-Medica Atenei Parmensis 91:175-179. https://doi.org/10.23750/abm.v91i3-s. 9511

Publisher's Note Springer Nature remains neutral with regard to jurisdictional claims in published maps and institutional affiliations. 